\title{
OpenOBS: Open-source, low-cost optical backscatter sensors for water quality and sediment-transport research
}

\author{
Emily F. Eidam ${ }^{1}$, Theodore Langhorst ${ }^{2}$, Evan B. Goldstein ${ }^{3}$, Mckenzie \\ Mclean $^{1}$ \\ ${ }^{1}$ Department of Marine Sciences, University of North Carolina, Chapel Hill, USA \\ ${ }^{2}$ Department of Geological Sciences, University of North Carolina, Chapel Hill, USA \\ ${ }^{3}$ Department of Geography, Environment, and Sustainability, University of North Carolina, Greensboro, \\ USA

\section{Key Points:} \\ - Optical backscatter sensors (OBSs) are commonly used in freshwater and marine \\ research to determine suspended particulate concentrations \\ - We designed an easy-to-construct open-source autonomous OBS sensor for $<\$ 50$ \\ in materials ( $<\$ 150$ produced), which yields smaller measurement errors than com- \\ mercial options $(\sim \$ 3000-5000)$ \\ - Data quality were comparable to results from commercial sensors, for mud sus- \\ pensions up to $1 \mathrm{~g} / \mathrm{L}$ (or greater) and sand suspensions on the order of $1-10 \mathrm{~g} / \mathrm{L}$ \\ in the lab and surf zone.
}




\section{Abstract}

Optical backscatter sensors (OBSs) are commonly used to measure the turbidity, or light obscuration, of water in fresh and marine environments and various industrial applications. These turbidity measurements are commonly calibrated to yield total suspended solids (TSS) or suspended sediment concentration (SSC) measurements for water quality, sediment transport, and diverse other research and environmental management applications. Commercial sensors generally cost $>\$ 1000-3000$. Here we leveraged simple, low-cost microprocessors, electronics, and housing components to design and construct open-source OBSs for $<\$ 150$ per unit. The circuit relies on a photodiode to sense the backscattered light, two stages of signal amplification, and a high resolution analogueto-digital convert to read the detected value. The instrument and logger utilize inexpensive, custom-printed circuit boards with through-hole soldering mounts; micro-SD card reader and real-time clock modules; and PVC housings with commercial end caps and epoxy-potted diode emitter and receiver. All parts are readily and publicly available, and minimal experience in soldering and coding is required to build and deploy the sensor. In lab and field tests, standard deviations were comparable to those measured by commercial sensors (2-3\% of the mean for suspended muds and $20-30 \%$ for suspended sands). These open-source sensors represent a useful advance in inexpensive sensing technology with broad applications across scientific and environmental management disciplines.

\section{Plain Language Summary}

Scientists often need to determine how much stuff is suspended in the water column - such as organic matter, mud, or sand. A typical way to measure this is with an optical backscatter sensor. The idea is that we shine a light in the water column, and measure how much light gets reflected back - more reflected light, more stuff in the water (and vice-versa). Anyone can buy instruments to do this for around $>\$ 1000$, but we wondered if we could build our own for less, especially given the rise in open source electronics. Using an Arduino we design and build an instrument for less than $\$ 150$. The electronics all sit in a length of PVC pipe, and compares well to commercial sensors. We have successfully tested the instrument in the lab, and at the beach. This inexpensive sensor allows researchers to envision experiments where there is a need for lots of sensors (i.e., along a river), and for experiments where the sensors might get lost or broken (i.e., during extreme events). 


\section{Introduction}

Optical backscatter sensors (OBSs) are instruments commonly used in aquatic research and environmental management to measure concentrations of particles suspended in water. The key components of an OBS are an infrared light emitting diode to illuminate the water, and a photodetector, which measures the intensity of that light scattered back to the sensor from particles in the water column (e.g., Downing, 2006). Through careful calibrations, the intensity of the backscattered light measured by the photodetector (reported as a voltage response) can be used as a proxy for the amount of particulates in the water, and converted to a measurement of turbidity, total suspended solids (TSS), or suspended-sediment concentration (SSC; see section 2 for a discussion of the differences between these parameters).

Modern OBSs were developed for scientific applications in the 1970s-1980s (Downing et al., 1981; Downing, 1983), and used in early studies to estimate the concentrations of sand suspended by wave action in the surf zone (e.g., Sternberg et al., 1989). Since then, they have been widely adopted for studies of sediment transport and water quality in diverse freshwater and marine systems. Applications include:

- Long-term monitoring of fluvial suspended-sediment concentrations, including at stations maintained by the U.S. Geological Survey (Schoellhamer and Wright, 2003; Rasmussen et al., 2009; Curtis et al., 2006);

- Studies of suspended-sediment delivery to floodplains and tributaries in freshwater systems (e.g., Hung et al., 2014; Nowacki et al., 2019);

- Studies of suspended-sediment fluxes (when turbidity sensors are paired with velocity measurements) in coastal environments including estuaries, intertidal flats, deltas, embayments, reef systems, sandy nearshore environments, open continental shelves, and laboratory analogues (e.g., Kineke and Sternberg, 1989; Birkemeier and Holland, 2001; Harris et al., 2004; Ogston et al., 2000; Hale et al., 2019; Talke and Stacey, 2008; Tinoco and Coco, 2018);

- Studies of water quality (e.g., nutrients and pollutants, including substances like mercury) in fluvial and coastal systems, including use of turbidity as a proxy for nutrient fluxes (Whyte and Kirchner, 2000; Stubblefield et al., 2007);

- Monitoring of dredge and disposal plumes (e.g., Reine et al., 2007; Jones et al., 2016; Wang and Beck, 2017); 
- Novel estimates of sediment deposition rates in coastal environments (Ridd et al., 2001; Thomas et al., 2003);

- Studies of light penetration in freshwater and marine environments (typically in conjunction with measurements of photosynthetically active radiation, or PAR, and light-scattering constituents other than sediment including colored dissolved organic matter, or CDOM, and chlorophyll-a; Glover et al., 2019; Storlazzi et al., 2015)

- Calibration of remotely sensed reflectance data to estimate suspended-sediment concentrations over large areas (e.g., Ouillon et al., 2004).

At present, several OBSs are commercially available to meet these needs. Sensors are typically offered in an autonomous configuration which includes a data logger and power source contained in a ruggedized waterproof housing, or integrated with other sensors (e.g., temperature, pressure/water level, conductivity, fluorometer, etc.) supported by a central logger or power source. An autonomous OBS costs $\sim \$ 3000-5000$, while a single OBS designed for integration with other sensors through a datalogger costs $\sim \$ 1000$. Total integrated instrument packages including OBSs typically cost $\sim \$ 5000$ to $>\$ 20,000$.

With the exception of a few comprehensive experiments (e.g., Birkemeier and Holland, 2001), research projects ranging from open-ocean mooring deployments to river monitoring stations commonly employ $<10$ OBSs at one time, in order to measure turbidity or SSC at a few discrete locations. The number of OBSs deployed is usually limited by the cost of the instruments, as well as the personnel resources for deployment and maintenance. However, lower-cost OBSs options could allow researchers to deploy large networks of dozens sensors and answer novel questions, e.g., regarding spatial variability in sediment fluxes across large river floodplains during high-discharge events.

Advances in open-source microcontrollers and single board computers have made instrument design and construction increasingly affordable and accessible to non-expert users. A growing number of projects have successfully leveraged Arduino, Raspberry PI, and other platforms in development of low-cost, open-source sensors for water-quality and hydrodynamics in lakes and oceans (e.g., Pearce, 2012; Bardaji et al., 2016; Godoy et al., 2018; Zhu et al., 2020; Koydemir et al., 2019; Kitchener et al., 2019; Temple et al., 2020; Lyman et al., 2020; Reeves et al., 2021; Kinar and Brinkmann, 2021). Because the heart of an OBS is a infrared light emitting diode and photodiode, which simply pro- 
vide a voltage reading with a generally linear response to the parameter of interest (see Downing, 2006 and section 2), the OBS is a prime candidate for re-development as an open-source instrument. Here we describe the fundamental principles by which an OBS operates, benefits and limitations in detecting environmental signals, and a comprehensive open-source design including validations against a commercially available OBS in the lab and field. This re-designed sensor provides a robust, low-cost alternative to commercially available models - it allows researchers to cost effectively design and implement experiments that require large numbers of sensors, or in environments where sensors could be lost or destroyed (i.e., extreme events).

\section{Background}

\subsection{Measurements of turbidity and particulate concentrations in sub- aqueous environments}

In natural environments, the amount of particulate matter suspended in water (river, lake, ocean, etc.) is commonly referred to as the "suspended sediment concentration" (SSC) if the particulates are lithogenic mineral grains (i.e., natural sediment eroded from rocks on the landscape), or "total suspended solids" (TSS) if the particulates include a mix of sediments and organic detritus. Measurements of SSC or TSS allow researchers to quantify the flux of sediment and/or organic material through waterways, as well as to what degree particulates contribute to light attenuation in water (relevant to ecology studies). Early attempts to quantify the amount of material suspended in water focused on the "turbidity" of the water, or degree to which light was obscured, by both particulate and dissolved matter. From these experiments, "nephelometer" instruments were developed, which measure the intensity of light scattered at a $90^{\circ}$ angle from the source. A greater concentration of particles results in a weaker signal, due to increased attenuation and scattering of light before it reaches the detector. Nephelometers are commonly calibrated to NTU (nepholmetric turbidity units) based on some standard amount of scattering from a white light source $(\sim 400-700 \mathrm{~nm})$.

Optical backscatter sensors are a type of nephelometer which measure the intensity of light scattered at angles of $90^{\circ}-180^{\circ}$ to the sensor. Modern OBSs typically operate at infrared or near-infrared wavelengths ( $\sim 850 \mathrm{~nm}$; Downing, 2006). Commercial sensors are commonly factory-calibrated to units of FTU (formazin turbidity units) or NTU 
through laboratory measurements of the voltage response to a range of known concentrations of formazin in suspension (formazin is a synthetic polymer of consistent size distribution). Depending on the study, researchers may also calibrate the raw voltage response or the FTU measurements to measurements of SSC or TSS. These calibrations are done by collecting water samples of varying SSC or TSS concentrations in situ together with OBS measurements, and then filtering the water samples to determine the mass of particulates. For TSS calibrations, samples are typically filtered through prepared $0.45 \mu \mathrm{m}$ pore-size nitrocellulose filters which are then dried, desiccated, and weighed. For SSC calibrations, samples are typically filtered through $1 \mu \mathrm{m}$ pore-size filters which are then combusted, in order to determine the mass of mineral grains in the absence of organic detritus. The measured SSC or TSS values are compared to the OBS measurements to obtain a linear relationship.

OBSs generally have a linearly increasing response to particle concentrations for values less than $4-10 \mathrm{~g} / \mathrm{L}$, followed by a constant response and then an exponentially decreasing response at greater concentrations (Kineke and Sternberg, 1992; Downing, 2006). Because natural sediment suspensions are commonly $<4 \mathrm{~g} / \mathrm{L}$ in rivers, lakes, and coastal zones (except for cases of sediment-gravity flows), this limitation is generally not relevant for OBS applications. However, within the linear response range, the scattering signal is sensitive to the type of particle (i.e., sediments of different roundness, plankton, bubbles, etc. can scatter light at different angles), the size of particle, and effects of multiple scattering (Downing, 2006). Of these, particle size effects are the most notable. While the particulate concentration (the signal of interest) can cause on the order of a 1000fold variation in instrument response, variations in particle size (even for the same mass concentration) can cause up to 100-fold difference in signal (Bunt et al., 1999; Downing, 2006). But in spite of these limitations, OBSs remain a standard choice for measurements of TSS and/or SSC in natural environments. Our goal here is to offer a cost-effective, open-source OBS that is easy to construct and adaptable to different applications, as an alternative to more costly commercial sensors.

\subsection{Existing open-source turbidity sensors}

Recent work on similar open-source OBSs has employed an analogue transmissometerstyle turbidity sensor, which has found practical commercial application for detection of water clarity in washing machines and dishwashers (e.g., Gravity Analogue Turbid- 
ity Sensor by DFRobot, dfrobot.com). This sensor yields an inverse relationship between turbidity and output voltage, with varying ranges depending on the circuit configuration (e.g., 2.8-3.8V for 0-1000 NTU, Eskin et al., 2019; 3.5-4 V for 0-170 NTU, Valenzuela et al., 2018). Gillet and Marchiori (2019) compared three of these commercially available units, configured for lab-style measurements, and concluded that they were of limited utility due to poor accuracy. In attempting to construct a more robust sensor, they noted problems with bubbles and ambient light, but achieved 5 NTU accuracy. Kinar and Brinkmann (2021) tested a similar sensor and found a non-linear response from $0.25-2.5 \mathrm{~V}$ in the $0-900 \mathrm{NTU}$ range. We tested one of these sensors in the lab and found an inconsistent response to various obstructions in the detection path, as well as a strong daylight sensitivity. Because of these issues of non-linear and variable responses, we chose instead to design a classic backscatter sensor using near-IR emitter and receiver mounted side-by-side. This design has been well-proven to have a linear response to particle concentration in a range of turbidities typical of many natural environments (approximately 0-1500 NTU).

Previous work has tested the utility of near-IR diode emitters and receivers as turbidity sensors. Adzuan et al. (2017) utilized one emitter with three receivers (mounted at $90^{\circ}$ or $180^{\circ}$ angles from the emitter) to measure Aluminum Sulfate coagulants (commonly used in water treatment processes). This sensor yielded a linear response spanning less than $0.2 \mathrm{~V}$ for turbidities of 0-100 NTU, and a linear response with different slope spanning approximately $0.1 \mathrm{~V}$ for turbidities of 200-1000 NTU. The sensor yielded values within $8-14 \%$ of those reported from a commercial unit. While measurements of this turbidity range are advantageous, the lack of a uniformly linear response may pose challenges in practical application.

Kelley et al. (2016) used a diode emitter TSL230R light-to-frequency receiver to create a classic, nephelometer-style turbidity sensor with detector mounted at a $90^{\circ}$ angle from the emitter. This sensor is well-suited for terrestrial water-quality sampling, and allows for measurement of a sample inside a cuvet. Results from development tests were linear within the 0.02-1000-NTU range tested, and yielded a standard deviation of up to 0.68 and root mean square error (RMSE) of $0.02-31.5 \%$ within the range tested.

Wiranto and Hermida (2016) used a TSL250 photodetector with 10-bit analogueto-digital converter (ADC) and real-time clock to produce a similar nephelometer-style 
sensor probe (with $90^{\circ}$ sensing angle). The response was linear across a $2-\mathrm{V}$ range for turbidities of approximately $0-100 \mathrm{NTU}$, with error of $1-12 \%$ relative to a commercial sensor, for tests run over five days.

Koydemir et al. (2019) tested both transmittance $\left(180^{\circ}\right)$ and nephelometric $\left(90^{\circ}\right)$ diode emitter/receiver sensor designs in a smartphone-based turbidity sensor platform, in which LED light is transmitted through optical fibers and detected by a CMOS (camera) sensor. The results were nearly linear, and they found that the nephelometer design worked well for turbidities up to 320 NTU (and yielded small standard deviations), but that the transmittance method worked better for turbidities up to 2000 NTU. Ultimately they developed a four-stage calibration curve for turbidity based on the intensity of light transmitted through the fibers.

Based on these recent promising advances in low-cost sensor technology, our goal here is to present a design for a transmittance-style backscatter sensor that (1) yields a signal at least as accurate as commercial sensors designed for submerged applications; (2) can be utilized in a wide range of turbidities characteristic of those found in natural waterbodies during diverse seasons and hydrodynamic conditions; and (3) is ruggedized to meet the demands of long-term submersion (i.e., for weeks to months).

\section{Methods: Sensor design}

\subsection{Diodes and circuit}

The OpenOBS circuit (Figures 1,2) is designed to accomplish three basic tasks: turbidity sensing, data logging, and power management. Turbidity is measured by illuminating the sample with a near-infrared emitting diode (IRED) and then measuring the intensity of light scattered back. For data logging, we use an Arduino Nano and cheap, off-the-shelf modules to read the sensor, keep track of time, and write data to a microSD card. Last, a clock module is used to switch the main batteries on for sampling, and off between measurements.

The first essential component of the OpenOBS is the analog sensing circuit (Figure 2), which emits near-infrared light and produces a voltage proportional to the light scattered back by the turbid water. The IRED has a peak wavelength of $870 \mathrm{~nm}$ and no focusing lens. Without a focusing lens, the emitted radiation follows a lambertian distribution and makes the receiver less sensitive to variations in alignment. The scattered 
light is sensed by a photodiode with peak sensitivity of $900 \mathrm{~nm}$ and an IR pass filter coating that blocks visible light.

We convert the micro-ampere-scale photodiode signal to a voltage using a transimpedance amplifier (TIA) in order to read the signal with an analog-to-digital converter. Selecting an operational amplifier (op amp) is an important design step, and is always a tradeoff between gain, bandwidth, and power consumption. Additionally, we need an op amp with low input bias current, because our TIA is sensing small changes in the signal current. We selected the MCP6244 op amp because it has rail-to-rail input and output, low bias current (1 pA nominal), and low power consumption. The last major consideration for the TIA is the input capacitance from the photodiode, which in our case is up to 72 $\mathrm{pF}$ when unbiased. This input capacitance can cause the TIA to oscillate and become unstable, and the introduction of a feedback capacitor is necessary to stabilize the TIA (Kay, 2012). While it is possible to calculate the required capacitance to stabilize the TIA, the stray capacitances in the printed circuit board are difficult to measure so we experimentally determined that $22 \mathrm{pF}$ stabilizes the signal at our sampling frequency. Three differential amplifiers are placed after the TIA stage to offset and further amplify the photodiode signal. Unlike many commercial sensors that reduce resolution in order to read high NTU values, the offset differential amplifiers allow full-resolution measurements in three bands of NTU values.

We use an Arduino Nano microcontroller to coordinate the data logging and battery management tasks of the OpenOBS. The Arduino platform allows quick and easy prototyping and code development, and the ATmega328P microprocessor on the Nano is one of the most common in the DIY and open-source electronics community. In the wake of the Arduino platform's popularity, many 'modules' are available that perform discrete tasks and integrate easily with Arduino. We take advantage of these cheap and easy-to-use modules to read the sensor voltage, keep track of the date and time, and write data to an SD card. The voltage output of the analog circuit is read by our analog-todigital converter (ADC) module. The ADS1115 ADC modules have a 4-channel 16-bit analog-to-digital converter with up to $16 \mathrm{x}$ of programmable gain. The four channels on the ADC are connected to the three differential amplifiers and the full-range TIA. A DS3231 real-time clock (RTC) module maintains the date and time with an accuracy of $+/-2$ minutes per year and temperature within $+/-3^{\circ} \mathrm{C}$. To complete one measurement, the 
Arduino pairs the ADC reading and a timestamp from the RTC and writes the data to a microSD card module using a standard communications protocol.

In addition to making high-quality measurements, a long battery life is essential for a sensor that will be deployed in remote locations and underwater. While powered on, the IRED consumes a majority of the power of the entire circuit but increases the signal-to-noise ratio. We remove the LED power indicators from the Arduino Nano and RTC modules and switch the IRED on only when taking measurements to save battery power. However, the greatest battery savings for most deployments comes from reducing power consumption between measurements. When measurement intervals exceed multiple minutes the average current draw is almost entirely determined by the power saving ability of the sensor between measurements, and minuscule improvements can add days to the battery life. Many existing open source loggers place each of the sensors and components into their respective low power modes for the sleep period (e.g. Beddows et al., 2018, Wickert et al., 2019), however our solution is to switch the main battery on and off using an electronic switch controlled by the alarm function of our RTC. The alarm output of the RTC is active low, and can pull the gate of a P-channel MOSFET low in order to reconnect the battery and restart the sensor at the appropriate time. When the main battery is disconnected (between measurements), The only component that remains powered is the RTC module, which draws a mere $3.5 \mu \mathrm{A}$ through the backup battery pin. At the end of each measurement wake cycle, we use the Arduino Nano to set the alarm for the next measurement and then instruct the RTC to disconnect the power to the rest of the sensor.

The circuits were assembled using custom-printed through-hole PC boards, which can be quickly obtained from online vendors for a few dollars per board (depending on the size of the batch). Nearly all of the circuit components are designed for through-hole soldering, a process which is fairly straightforward (as opposed to surface-mount soldering). With the exception of the diode emitter and receiver which are potted in epoxy after being mounted on a separate piece of protoboard, the entire instrument assembly is mounted to the custom PC board and can be slid out of the housing for replacement of batteries and general inspection. 


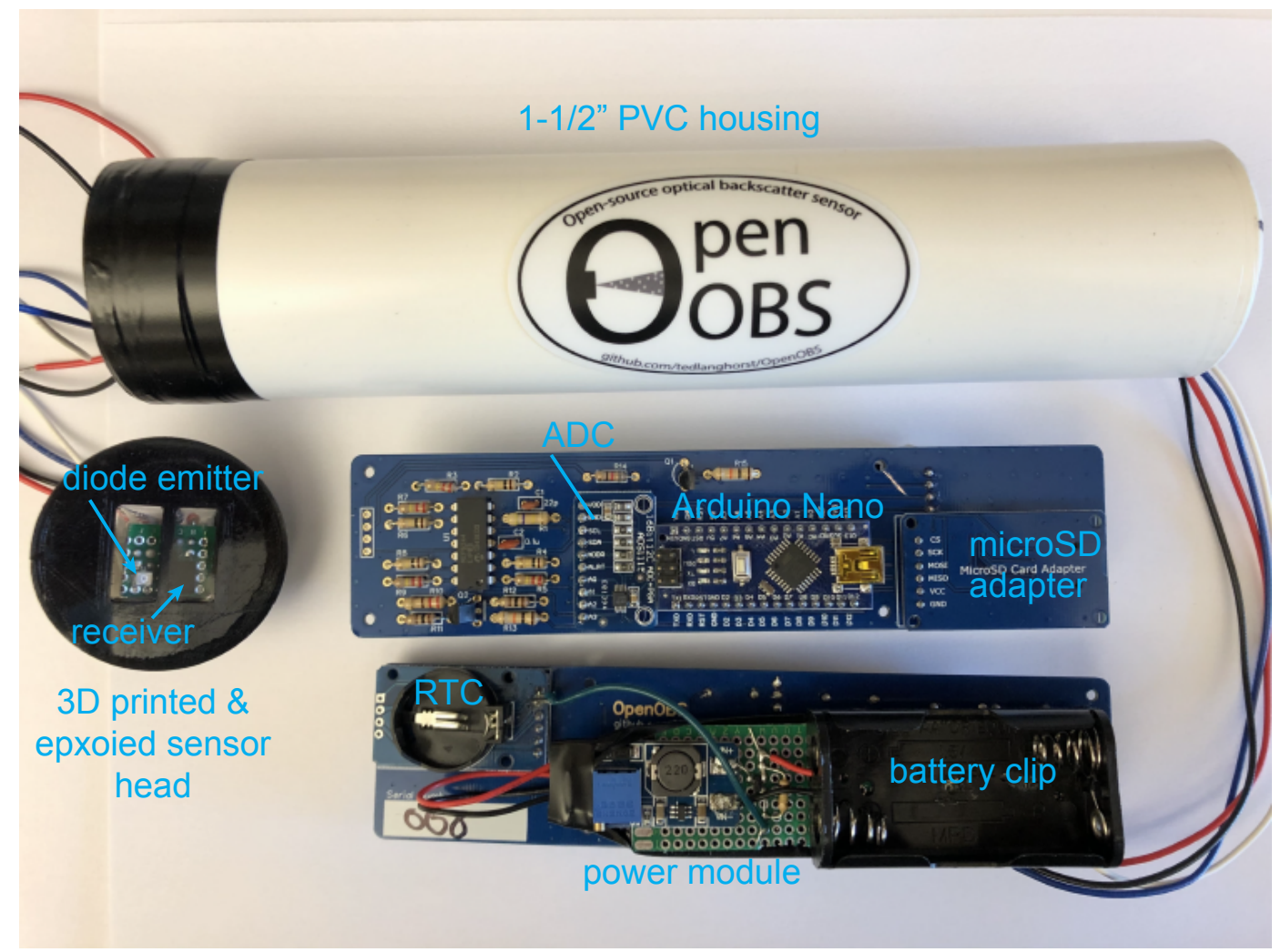

Figure 1: OpenOBS instrument. Parts shown include the housing with endcap installed, an example endcap that has not yet been installed, and the front and back of the circuit board with breakout boards and peripherals attached. A commercial watertight compression plug (not shown) is added to the right end to complete the housing. 


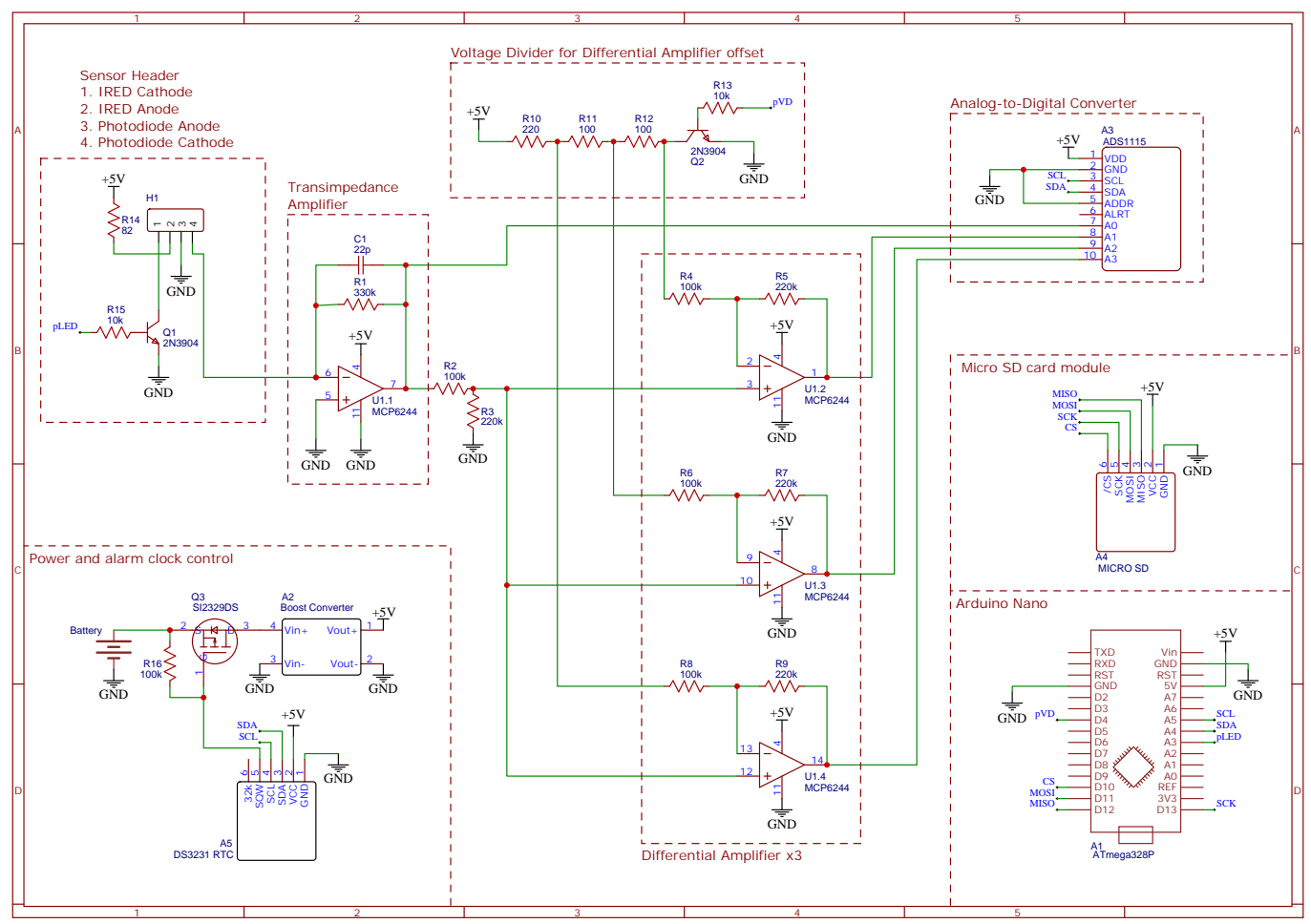

Figure 2: OpenOBS circuit diagram.

\subsection{Housing}

In order to build a rugged, waterproof housing, we chose inexpensive and sturdy 1-1/2" diameter schedule 40 PVC pipe and plumbing-style compression plugs (rated to 17 PSI) for the basis of the sensor shell. For the sensor end cap, we 3D printed a custom bracket which holds the emitter/receiver board. The bracket includes a small divider which separates the emitter and receiver, to reduce contamination of the backscattered signal by the emitted light. The emitter/receiver were potted inside the 3D-printed head using a two-part, optically clear, hard epoxy. In order to minimize entrained bubbles, the epoxy was poured into the heads which were placed on a smooth silicone mat, and then each assembly was vibrated, heated, and cured overnight in a pressure pot (which required a small air compressor). The finished sensor heads were then mounted on the PVC pipe using PVC sealant with backup marine epoxy. For field deployments, we complemented the caps at both ends with electrical tape.

We tested three different epoxies rated as optically clear with good hardening ability. The response of the backscatter sensor was tested outdoors using an ASD FieldSpec 
3 spectrometer for each epoxy type. All of the epoxies had similar near-infrared transmissivity and caused a comparable focusing effect which amplified the sensor response. We chose an epoxy which allowed for relatively easy removal of bubbles and a good hardness when dry.

The custom-printed PC boards were sized to fit snugly in the housing. The battery clip was fastened to the board to reduce movement. The compression cap has a pressure rating of $17 \mathrm{psi}$ or approximately 12 dbar, meaning that the sensor can withstand water depths of approximately 12 meters (assuming comparable integrity of the epoxied sensor head).

\section{Results: Testing and validation}

Testing was done in the lab to address several questions: (1) intercomparison with commercial sensor response for dilutions of a formazin turbidity calibration standard; (2) intercomparison with commercial sensor response for mixtures of natural sediments; and (3) temperature dependence. Our goal was to demonstrate the suitability of the sensors for use in warm and cold natural environments for a range of TSS values typically encountered in river and shallow marine environments, e.g., $\sim 10-1200 \mathrm{mg} / \mathrm{L}$.

\subsection{Formazin calibration}

Formazin is a synthetic polymer suspension, which is commonly used to calibrate commercial turbidity sensors. We used Sigma-Aldrich and Hach turbidity standards at stock concentrations of $20,100,500$, and 1000 NTU to calibrate the turbidity signal of the OpenOBS sensors, at room temperature (approximately $22^{\circ} \mathrm{C}$ ). The commercial sensor and the three OpenOBS sensors that were tested all yielded results that were linearly related to the turbidity of the stock solution, with correlation coefficients of 1.00 (Figure 3). The slopes of the calibration lines for the OpenOBS sensors varied from 0.00190.0025 , and the intercepts were $0.25-0.28$.

\subsection{Temperature sensitivity tests}

The performance of the OpenOBSs under different temperature conditions was tested by measuring tap water and stock formazin solutions at room temperature $\left(22^{\circ} \mathrm{C}\right)$ and in a cold room $\left(\sim 10^{\circ} \mathrm{C}\right)$. The sensors again exhibited linear responses. The signals from 

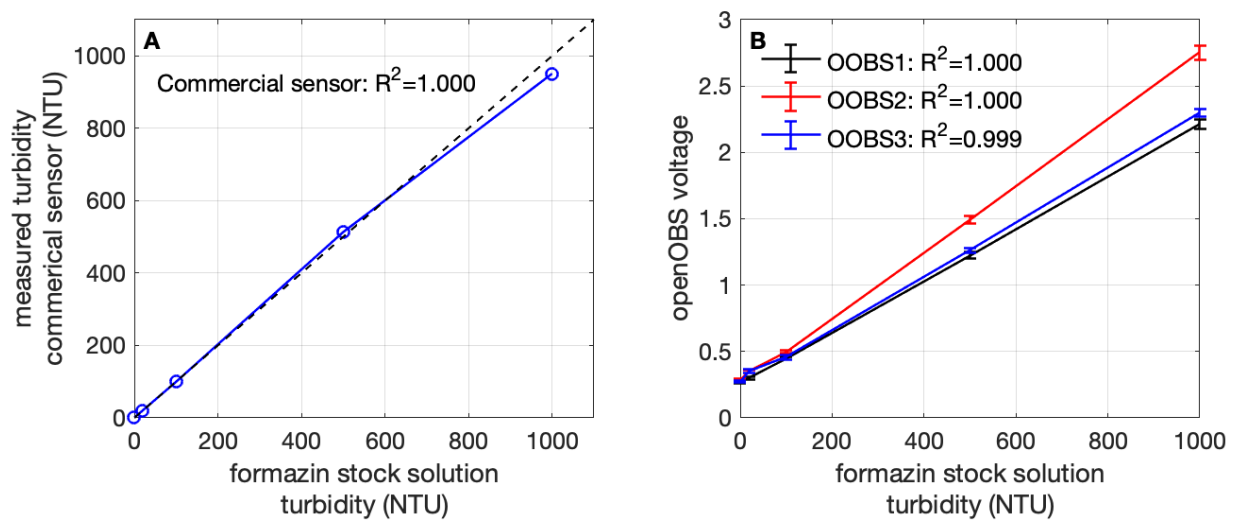

Figure 3: Formazin calibration. (A) Measured turbidity (commercial sensor) versus formazin stock solution turbidity. (B) OpenOBS voltage response versus formazin stock solution turbidity. $\mathrm{R}^{2}$ values for the linear best-fit lines (not shown) are given.

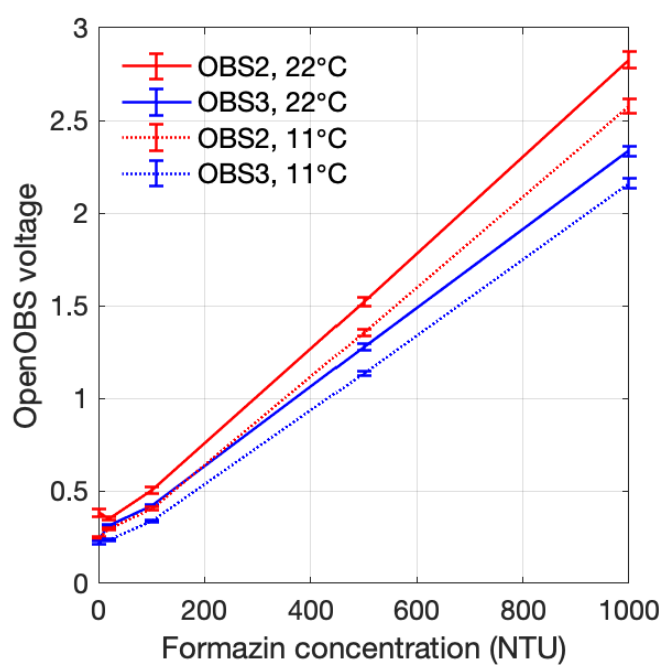

Figure 4: Results of the temperature tests, using tap water and stock formazin standards. Solid lines denote room-temperature tests and dashed lines denote cold room tests.

the cold room tests were $65-92 \%$ of the warm test values for OpenOBS2, and $75-92 \%$ of the warm test values for OpenOBS3 (Figure 4).

\subsection{Natural sediment calibration}

Two laboratory suspended-sediment tests were performed using natural sediments: one with sand from the surf zone test site at Duck, NC (FRF facility), and one with clay and silt from the White Oak Estuary in $\mathrm{NC}(<63 \mu \mathrm{m}$ sediment). In each test, increasing sediment concentrations were mixed in a 3 -L container on a stir plate. Two OpenOBS 
Table 1: Laboratory suspended-sand calibration results. Sand from the surf zone test site at Duck, NC was mixed in solution and measured with a commercial sensor (RBR), OOBS2, and OOBS3.

\begin{tabular}{|c|c|c|c|c|c|c|c|c|c|}
\hline \multirow[b]{2}{*}{$\begin{array}{l}\text { SSC } \\
(\mathrm{g} / \mathrm{L})\end{array}$} & \multicolumn{3}{|c|}{ RBR } & \multicolumn{3}{|c|}{ OOBS2 } & \multicolumn{3}{|c|}{ OOBS3 } \\
\hline & $\begin{array}{l}\text { mean Tu } \\
\text { (NTU) }\end{array}$ & $\begin{array}{c}\sigma \\
(\mathrm{NTU})\end{array}$ & $\begin{array}{c}\sigma \% \text { of } \\
\text { mean }\end{array}$ & $\begin{array}{l}\text { mean } \\
\text { (volts) }\end{array}$ & $\begin{array}{c}\sigma \\
\text { (volts) }\end{array}$ & $\begin{array}{c}\sigma \% \text { of } \\
\text { mean }\end{array}$ & $\begin{array}{l}\text { mean } \\
\text { (volts) }\end{array}$ & $\begin{array}{c}\sigma \\
\text { (volts) }\end{array}$ & $\begin{array}{c}\sigma \% \text { of } \\
\text { mean }\end{array}$ \\
\hline \multicolumn{10}{|l|}{ Sand* } \\
\hline 0.00 & 2.96 & 0.13 & 4.3 & 0.227 & 0.0066 & 2.9 & 0.275 & 0.0061 & 2.2 \\
\hline 0.506 & 12.8 & 4.3 & 33 & 0.232 & 0.0066 & 2.9 & 0.294 & 0.0091 & 3.1 \\
\hline 2.65 & 51.6 & 15 & 30 & 0.266 & 0.024 & 9.0 & 0.348 & 0.045 & 13 \\
\hline 5.53 & 119 & 34 & 28 & 0.335 & 0.055 & 17 & 0.507 & 0.090 & 18 \\
\hline 10.0 & 200 & 49 & 24 & 0.464 & 0.10 & 22 & 0.703 & 0.16 & 23 \\
\hline 20.4 & 304 & 71 & 23 & 0.590 & 0.12 & 20 & 1.02 & 0.26 & 25 \\
\hline \multicolumn{10}{|l|}{ Mud $^{+}$} \\
\hline 0.00264 & 3.37 & 0.083 & 2.5 & 0.237 & 0.011 & 4.8 & 0.24 & 0.013 & 5.2 \\
\hline 0.0800 & 47.5 & 1.2 & 2.5 & 0.247 & 0.0090 & 3.7 & 0.24 & 0.0053 & 2.2 \\
\hline 0.198 & 109 & 2.6 & 2.4 & 0.306 & 0.0080 & 2.6 & 0.29 & 0.0087 & 3.0 \\
\hline 0.281 & 154 & 3.5 & 2.3 & 0.367 & 0.0087 & 2.4 & 0.34 & 0.0087 & 2.6 \\
\hline 0.373 & 197 & 5.3 & 2.7 & 0.427 & 0.0091 & 2.1 & 0.39 & 0.010 & 2.6 \\
\hline 0.908 & 448 & 10 & 2.2 & 0.801 & 0.013 & 1.7 & 0.70 & 0.014 & 1.9 \\
\hline 1.72 & 703 & 21 & 2.9 & 1.17 & 0.035 & 3.0 & 0.95 & 0.021 & 2.3 \\
\hline
\end{tabular}

* Sand: $\mathrm{d}_{10}=158 \mu \mathrm{m}, \mathrm{d}_{50}=315 \mu \mathrm{m}, \mathrm{d}_{90}=626 \mu \mathrm{m}$

+ Mud: $\mathrm{d}_{10}=2.72 \mu \mathrm{m}, \mathrm{d}_{50}=17.7 \mu \mathrm{m}, \mathrm{d}_{90}=48.8 \mu \mathrm{m}$

sensors and one commercial sensor were submerged together. Subsamples of each sediment/water mixture were collected and filtered on prepared $0.45 \mu \mathrm{m}$ nitrocellulose filters to determine the total suspended solids concentrations.

For the sand test, total suspended solids ranged from 0.50 to $20 \mathrm{~g} / \mathrm{L}$ (neglecting the first sample, which was tap water; Table 1). The commercial sensor yielded turbidity values of 13-300 NTU, with standard deviations that were $23-33 \%$ of the mean values. By comparison, the OpenOBS sensors yielded signals of 0.23-1.0 V with standard deviations that were $3-25 \%$ of the mean values. All sensors demonstrated good linearity within the TSS range sampled $\left(\mathrm{R}^{2} \geq 0.968\right)$.

For the mud test, total suspended solids ranged from 0.080 to $1.7 \mathrm{~g} / \mathrm{L}$ (neglecting the first sample, which was tap water; Table 1). The commercial sensor yielded turbidity values of $48-700 \mathrm{NTU}$, with standard deviations that were $2.2-2.9 \%$ of the mean values. The OpenOBS sensors yielded signals of 0.24-1.2 V with standard deviations that were $1.7-3.7 \%$ of the mean values. All sensors demonstrated good linearity within the TSS range sampled $\left(\mathrm{R}^{2} \geq 0.983\right)$. 

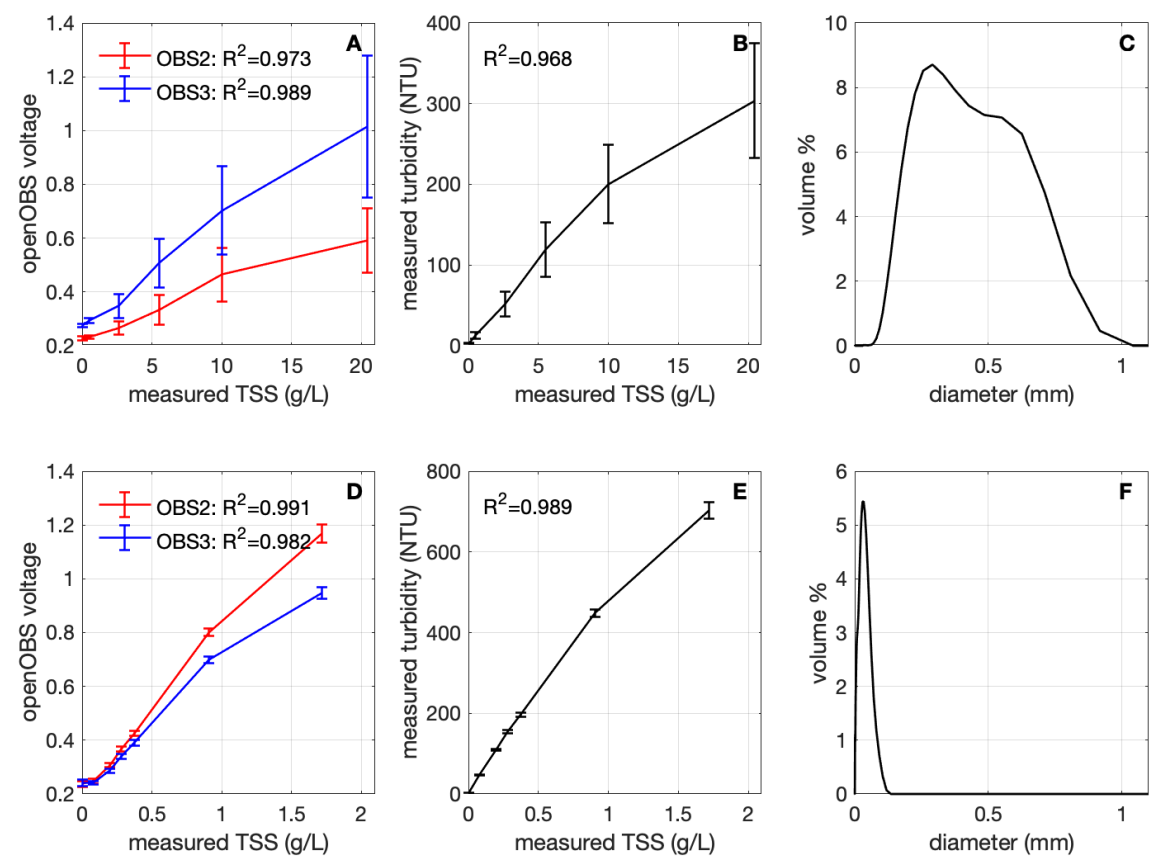

Figure 5: Natural sediment calibrations. (A) OpenOBS voltages versus TSS for mixtures of sand from Duck, NC. (B) Commercial sensor turbidities versus TSS for the sand test. (C) Particle-size distribution (by volume percent) of Duck surf zone sand used in A and B. (C) OpenOBS voltages versus TSS for mixtures of mud $(<63 \mu \mathrm{m})$ from the White Oak Estuary in NC. (D) Commercial sensor turbidities versus TSS for the mud test. Particle-size distribution of White Oak muds used in D and E. 

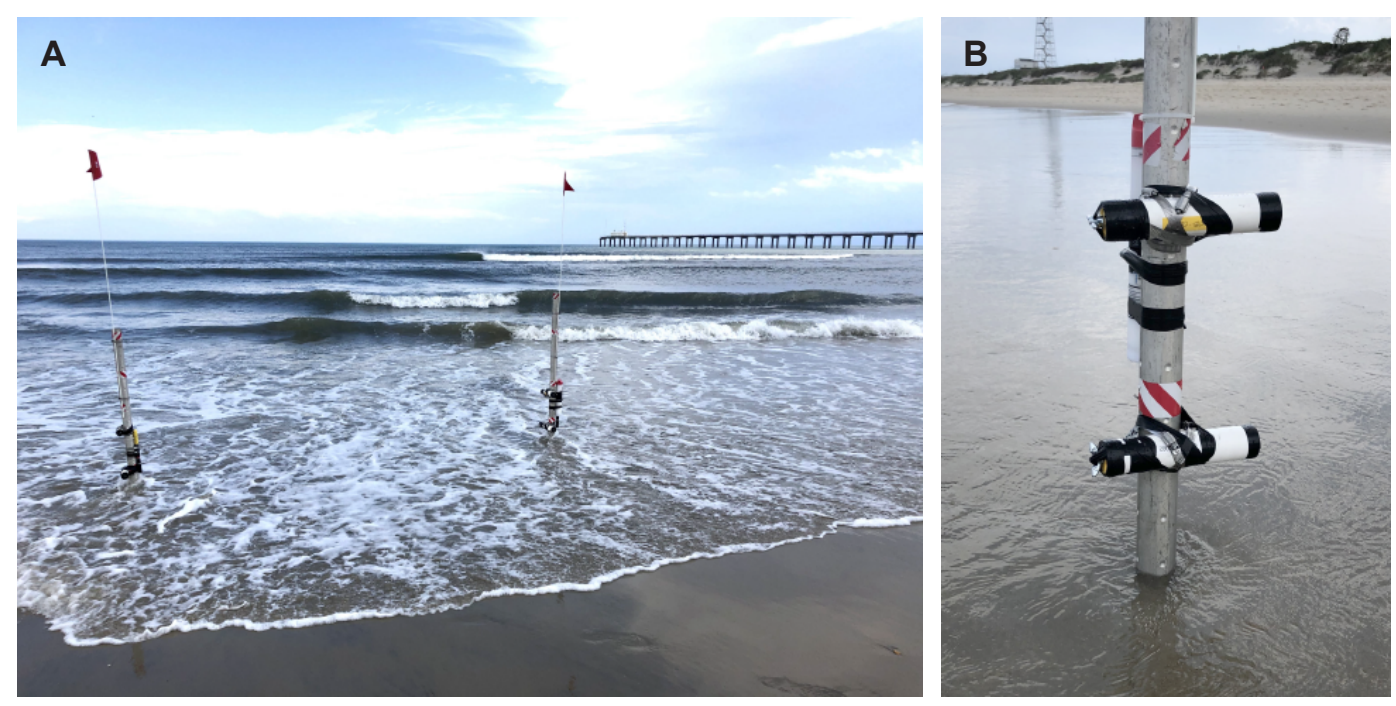

Figure 6: Surf-zone deployment at the FRF site in Duck, NC (May 2021). (A) Sensors were mounted on poles jetted into the surf zone at low tide. Deployments lasted 24-48 hours, and maximum inundation during high tide was on the order of $1 \mathrm{~m}$. (B) Mounting detail.

\subsection{Field test}

Several OpenOBSs were deployed in the surf zone at the US Army Corps of Engineers Field Research Facility (FRF) in Duck, NC (Figure 6) for periods of 24-48 hours between 10 and 14 May, 2021. Sensors were mounted within $0.5 \mathrm{~m}$ of the bed on poles jetted into the sand at low tide, and were located in the field of view of a beach-scanning lidar system (O'Dea et al., 2019). Commercial turbidity, water-level, and wave sensors were deployed concurrently. Maximum inundation during the deployments was on the order of $1 \mathrm{~m}$, and significant wave heights were on the order of 0.4-1.4 m (based on FRF 4.5m AWAC wave data accessed from https://frfdataportal.erdc.dren.mil). Bed sand was collected at the pole locations before and after deployments. Grain-size distributions were measured at UNC using a laser diffraction particle sizer. Samples were well-sorted with median size $\left(d_{50}\right)$ of $315 \mu \mathrm{m}$ (Figure $5 \mathrm{c}$ ). Sediment deposition on the order of 1-10 cm occurred at the base of each pole during inundation periods.

Following two or more periods of inundation and wave breaking in the surf zone, the OpenOBSs remained watertight. During periods of subaerial exposure, the signal was high (near $5 \mathrm{~V})$ at night and was fully saturated at $5 \mathrm{~V}$ during the day.

The OpenOBSs returned backscatter signals characterized by strong periodicity, with similar frequency as the wave-driven water-level fluctuations (Figure 7). During day- 
time rising tides as the sensors were inundated, the output became gradually less saturated (Figure 7C). Peaks in the signal generally corresponded to peaks in the waterlevel record, though not all water-level fluctuations caused a strong response in the OpenOBS (Figure 7D, E).

\section{Discussion}

\subsection{Design considerations}

The OpenOBS successfully measures the optical backscatter signal of particle suspensions, with accuracy comparable to or better than more costly commercial instruments. Here we note some design considerations for the sensors.

First, we chose to build the circuit using individual diode emitters and receivers mounted on a custom board, rather than using a more "off-the-shelf" turbidity sensor. We had tested a pre-made diode emitter/receiver breakout board (TCRT5000, designed as a sensor for self-driving model cars) as well as a transmissometer-style washing machine sensor (DFRobot Gravity sensor; e.g., Eskin et al., 2019). The transmissometerstyle sensor gave ambiguous results, and the output signal from teh TCRT5000 gave an impractically small voltage range. By using an individually selected diode emitter and receiver, we were able to better control the gain, amplification, and quality of the output signal — and also mount the parts on a custom breakout board which was easier to integrate into a watertight housing. In choosing the diode emitter, we tested four different models, and chose the diode that gave a good range in voltage response and linear signal when paired with our photodiode.

The housings were designed to be cheap and easy to construct using off-the-shelf components plus 3D printed and epoxied end caps. In practice, it may be desirable to use a more elaborate threaded end cap to allow for a better pressure rating, and to reconfigure the epoxied end to accommodate a side-looking diode (which would allow for easier mounting on poles). It is worth noting that the epoxy does require some effort to remove bubbles. It is possible that more expensive, manufactured sensor faces could be integrated into the housings in order to avoid pouring and curing epoxy. 

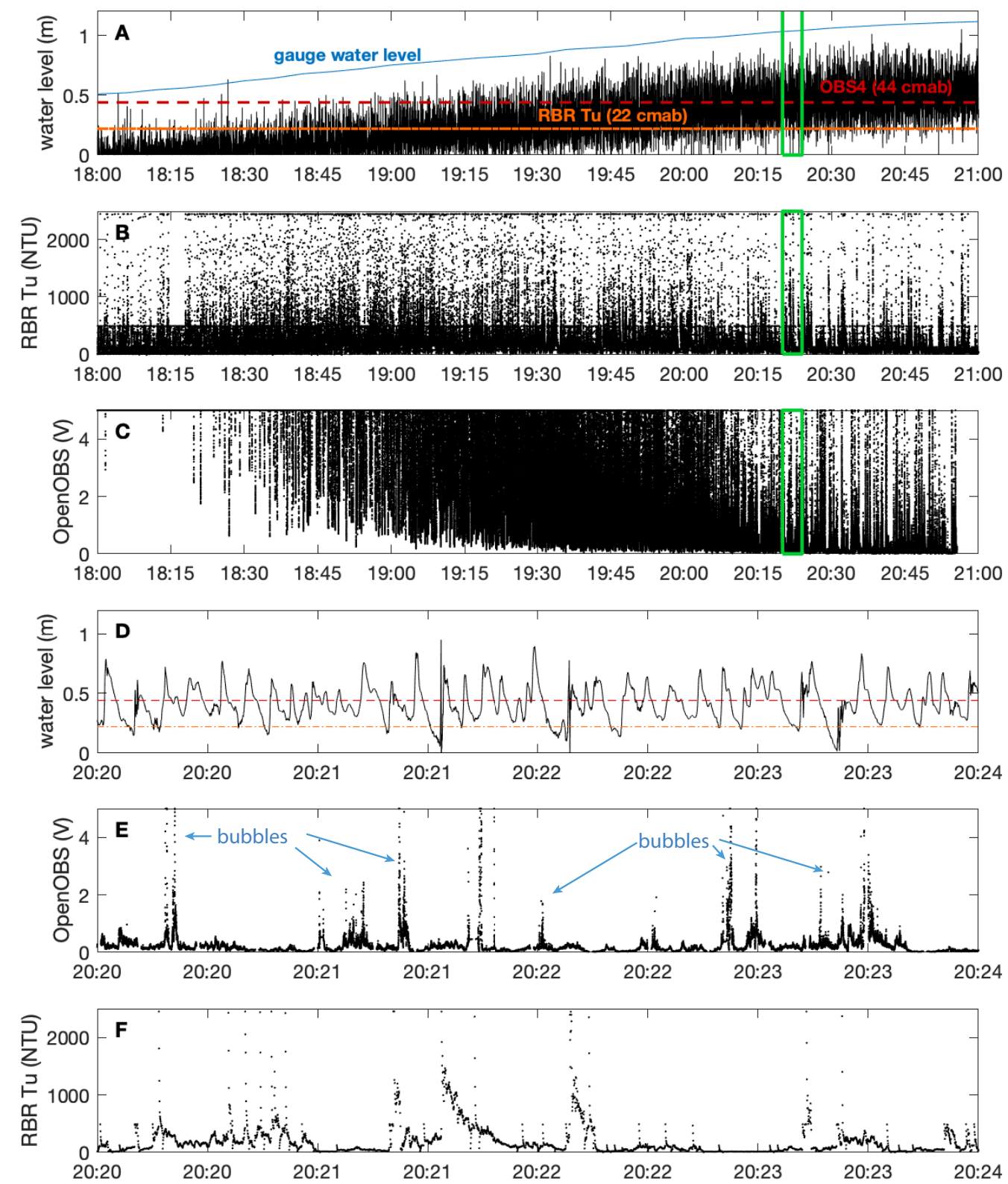

Figure 7: Surf zone test results from 13 May. (A) Gauge water level (from FRF pier, blue) and measured water level at one of the two instrument poles (black). Elevations of OBS4 and a commercial sensor (RBR Tu) are shown. (B) Commercial sensor turbidity results (16 Hz). (C) OpenOBS results $(200 \mathrm{~Hz})$. (D) Expanded view of the water-level record for 4 minutes on 13 May. (E) Expanded view of the OpenOBS record. (F) Expanded view of the commercial sensor turbidity record. 


\subsection{Instrument performance in lab and environmental tests}

The sensors performed well in lab tests. In the formazin tests, the OpenOBSs yielded standard deviations that were within $2 \%$ of the mean, compared to $0.5 \%$ for the calibrated commercial sensor. The sensors also exhibited good linearity, as expected for turbidities comparable to TSS concentrations of $<4000 \mathrm{mg} / \mathrm{L}$ (e.g., Downing, 2006). In natural sediment tests, the sensors also performed well, with standard deviations that were comparable to or better than the commercial sensors (Table 1). Instrument responses were linear within $1 \mathrm{~g} / \mathrm{L}$ for suspended muds, and within $20 \mathrm{~g} / \mathrm{L}$ for suspended sands.

Both the OpenOBSs and commercial sensors were sensitive to particle size effects. Each sensor had a similar voltage response between sand and mud suspensions, despite a 10-fold greater suspended sand concentration (Table 1). For mud suspensions, the standard deviations from each sensor were $\sim 2-3 \%$ of the mean. For sand suspensions, the standarad deviations were $\sim 20-30 \%$ of the mean. These results are consistent with past observations about the sensitivity of OBSs to different sizes and shapes of sediment - namely that particle size effects (including flocculation) can cause up to a 100-fold change in the signal and particle shape can account for $\sim 1 \%$ or more variation in the signal (Benns and Pilgrim, 1994; Bunt et al., 1999; Downing, 2006). The ability of the sensors to effectively measure suspended sand concentrations within $20 \mathrm{~g} / \mathrm{L}$ is an interesting result, since past studies have reported that sensors yield a linear response within $\sim 4 \mathrm{~g} / \mathrm{L}$ - but specifically for muddy suspensions (e.g., Downing, 2006). The usable signal for high concentrations of sand illustrates the utility of these sensors for a range of natural and lab conditions, given careful calibration with sediment from the environment (i.e., standard practice for OBSs).

In temperature tests, the commercial sensor yielded nearly identical results (within $0.5 \%)$ for the cold and warm environments. The OpenOBSs exhibited more variation ( 10$30 \%$ ), due to the lack of a temperature regulator. This effect arises because of variation in the intensity of the light emitted by the diode at different ambient temperatures. This effect can be addressed by calibrating the sensor in a similar temperature as the environment where it was deployed (which can be determined by the internal temperature record if deployed long enough to reach ambient temperature, or by using an external temperature logger). 
The OpenOBSs performed very well in the surf zone, which represents one of the harshest and most noise-filled environments in which these types of sensors can be expected to operate. The sensors produced a periodic response similar to that recorded by a commercial sensor (Figure 7E, F). There are several differences that should be noted. The OpenOBS signal tends to be saturated when exposed subaerially at low tide, and during periods of shallow water depth. This effect was not observed in the commercial sensor (likely due to the inclusion of a daylight filter). This is not necessarily a limitation, however. Downing et al. (1981) noted that OBSs which use a low-pass optical filter should be operable to within $25 \mathrm{~cm}$ of the water surface, due to rapid attenuation of IR light in seawater. For water depths shallower than $25 \mathrm{~cm}$, the signal is likely too saturated with bubbles, and any signal of sediment resuspension should not be trusted. In the 13 May results, the commercial sensor (Figure 7B) blocks daylight so effectively that it yields a signal which seems believable even during periods of less than $20 \mathrm{~cm}$ inundation (18:00 to 18:30), which may be erroneously analyzed if water levels are not carefully accounted for in post-processing. The OpenOBS data thus offer an advantage in that periods of daylight exposure - as well as periods of very shallow water when bubbles are likely a major part of the signal - can be clearly recognized and thus removed and/or properly interpreted from the data (Figure 7C).

For periods of greater than $\sim 0.5 \mathrm{~m}$ inundation, the OpenOBS performs well next to a commercial sensor data (Figure 7E, F). The commercial sensor, which was mounted $\leq 22 \mathrm{~cm}$ above the bed (cmab), yielded a somewhat stronger signal of resuspension relative to the OpenOBS mounted at $\leq 44 \mathrm{cmab}$, which is expected given the difference in elevation. The OpenOBS yielded a response during some periods when the commercial sensor did not, which we interpret as a result of breaking waves, rollers, and bubbles high in the water column (not registered by the lower sensor) without any significant sand resuspension near the bed. The magnitudes of the OpenOBS response also suggest that these signals are bubbles - in lab calibrations, voltages on the order of 0.6-1 V corresponded with suspended-sand concentrations of up to $\sim 20 \mathrm{~g} / \mathrm{L}$ (Table 1). Past studies surf-zone sand resuspension yielded concentrations of $\sim 1 \mathrm{~g} / \mathrm{L}$ or less more than $5 \mathrm{~cm}$ from the bed (Sleath, 1982; Osborne and Vincent, 1996; Vincent and Hanes, 2002), and so it seems unreasonable to interpret the 1.5-5 V signal at $\sim 40 \mathrm{cmab}$ (Figure $7 \mathrm{C}$ ) as sand concentrations $>20 \mathrm{~g} / \mathrm{L}$. These results are consistent with past work indicating that bubbles can cause a $25 \%$ increase in voltage response (Puleo et al., 2006). Thus, the obvious sen- 
sitivity of the instrument to both bubbles and daylight may allow for ease of post-processing after considering the environment of deployment.

\subsection{Practical application and future expansion}

The OpenOBS has proven to be useful for detection of suspended muds and sands in natural environments, including harsh surf-zone environments. Care should be taken to achieve successful deployments and reliable results - specifically:

- Avoid deploying sensors in water depths beyond the pressure limit of the end caps. Housings with higher pressure ratings could perhaps be manufactured for a few hundred dollars per sensor, which would still keep the cost at $<50 \%$ of existing commercial models.

- Be wary of contamination by daylight and bubbles. Through knowledge of the instrument depth and water level, and conscientious post-processing of data (to eliminate high voltages indicative of bubbles), reliable data may be obtained.

- In flume studies where water velocities may be low, monitor sensor faces to ensure that bubbles are not accumulating (mounting orientation can impact this).

- Beware of biofouling effects, which plague all OBSs in environments where algae, barnacles, and other debris may obscure the sensor (Dolphin et al., 2001; Ridd and Larcombe, 1994).

- Calibrate each sensor before and after deployments. This may be done in the lab using formazin and/or natural sediments, as well as by using water samples from the field (filtered to obtain TSS or SSC).

- Choose batteries and deployment schemes (e.g., sampling frequency) carefully to maximize data collection.

In the future, expansion of these sensors to include external logging and power capability (e.g., for seasonal deployment along a river bank) and real-time data transmission (e.g., in conjunction with an oceanographic mooring deployment) would allow for greater functionality. The availability of companion parts and adaptability of the OpenOBS make these viable options in the near-term. 


\section{Conclusions}

The OpenOBS is an open-source, low-cost turbidity sensor which can be constructed for less than $\$ 150$, or less than $5 \%$ of the cost of comparable commercial sensors. In laboratory and field tests, the OpenOBS yields calibrated total suspended solids measurements of comparable accuracy as commercial turbidity sensors. The OpenOBS is capable of sampling faster than commercial sensors $(100-200 \mathrm{~Hz}$ versus $16 \mathrm{~Hz})$ without significant loss of data quality, and has been engineered to run for weeks to months on an interval sampling scheme when equipped with high-capacity lithium batteries. The lowcost and good data quality of this sensor makes this an attractive option for researchers who need to deploy large numbers of sensors and/or to deploy sensors in high-risk environments. This advancement allows for previously unrealized environmental measurement capability of sediment transport, and turbidity as a water-quality parameter.

\section{Code availability}

The code, wiring diagram, hardware bill of materials, and 3D printed endcap design files are all available at: https://github.com/tedlanghorst/OpenOBS

\section{Acknowledgments}

We thank Carly Richardson for assistance writing the early Arduino code, Tom Eidam for advising the early circuit design, and Dr. Nick Cohn and the field support staff at USACE-FRF for assistance conducting surf zone validation tests. We also thank the Reynolds Foundation for funding this work through a UNC grant to PI Eidam.

\section{References}

Adzuan, M.A., Rahiman, M.H.F. and Azman, A.A., 2017, August. Design and development of infrared turbidity sensor for aluminium sulfate coagulant process. In 2017 IEEE 8th Control and System Graduate Research Colloquium (ICSGRC) (pp. 105109). IEEE.

Bardaji, R., Sánchez, A.M., Simon, C., Wernand, M.R. and Piera, J., 2016. Estimating the underwater diffuse attenuation coefficient with a low-cost instrument: The KdUINO DIY buoy. Sensors, 16(3), p.373. 
Beddows, P. A., Mallon, E. K. (2018). Cave pearl data logger: A flexible Arduino-based logging platform for long-Term monitoring in harsh environments. Sensors, 18(2), 530.

Benns, E. J., Pilgrim, D. A. (1994). The effect of particle characteristics on the beam attenuation coefficient and output from an optical backscatter sensor. Netherland Journal of Aquatic Ecology, 28(3), 245-248.

Birkemeier, W.A. and Holland, K.T., 2001. The corps of engineers field research facility: more than two decades of coastal research. Shore and Beach, 69(1), pp.3-12.

Bunt, J.A., Larcombe, P., and Jago, C.F., 1999. Quantifying the response of optical backscatter devices and transmissometers to variations in suspended particulate matter. Continental shelf research, 19(9), 1199-1220.

Curtis, J.A., Flint, L.E., Alpers, C.N., Wright, S.A. and Snyder, N.P., 2006. Use of sediment rating curves and optical backscatter data to characterize sediment transport in the upper Yuba River watershed, California, 2001-03. USGS Scientific Investigations Report 2005-5246, Sacramento.

Dolphin, T. J., Green, M. O., Radford, J. D. J., Black, K. P. (2001). Biofouling of optical backscatter sensors: Prevention and analytical correction of data. Journal of Coastal Research, 334-341.

Downing, J., 2006. Twenty-five years with OBS sensors: The good, the bad, and the ugly. Continental Shelf Research, 26(17-18), pp.2299-2318.

Downing, J., 1983. An optical instrument for monitoring suspended particulates in ocean and laboratory. In Proceedings OCEANS'83 (pp. 199-202). IEEE.

Downing, J.P., Sternberg, R.W., Lister, C.R.B., 1981. New instrumentation for the investigation of sediment suspension processes in the shallow marine environment. Marine Geology, 42(1-4), 19-34.

Eskin, M.G., Torabfam, M., Psillakis, E., Cincinelli, A., Kurt, H. and Yüce, M., 2019. Real-time water quality monitoring of an artificial lake using a portable, affordable, simple, arduino-based open source sensor. Environmental Engineering-Inženjerstvo okoliša, 6(1), pp.7-14. 
Gillett, D. and Marchiori, A., 2019. A low-cost continuous turbidity monitor. Sensors, 19(14), p.3039.

Glover, H.E., Ogston, A.S., Miller, I.M., Eidam, E.F., Rubin, S.P. and Berry, H.D., 2019. Impacts of Suspended Sediment on Nearshore Benthic Light Availability Following Dam Removal in a Small Mountainous River: In Situ Observations and Statistical Modeling. Estuaries and Coasts, 42(7), pp.1804-1820.

Godoy, A.C., Nakano, A.Y., Siepmann, D.A.B., Schneider, R., Pfrimer, F.W.D. and Santos, O.O., 2018. Snapshots analyses for turbidity measurements in water. Water, Air, Soil Pollution, 229(12), pp.1-11.

Hale, R., Bain, R., Goodbred Jr, S. and Best, J., 2019. Observations and scaling of tidal mass transport across the lower Ganges-Brahmaputra delta plain: implications for delta management and sustainability. Earth Surface Dynamics, 7(1).

Harris, P.T., Hughes, M.G., Baker, E.K., Dalrymple, R.W. and Keene, J.B., 2004. Sediment transport in distributary channels and its export to the pro-deltaic environment in a tidally dominated delta: Fly River, Papua New Guinea. Continental Shelf Research, 24(19), pp.2431-2454.

Hung, N.N., Delgado, J.M., Güntner, A., Merz, B., Bárdossy, A. and Apel, H., 2014. Sedimentation in the floodplains of the Mekong Delta, Vietnam. Part I: suspended sediment dynamics. Hydrological Processes, 28(7), pp.3132-3144.

Jones, R., Bessell-Browne, P., Fisher, R., Klonowski, W. and Slivkoff, M., 2016. Assessing the impacts of sediments from dredging on corals. Marine Pollution Bulletin, 102(1), pp.9-29.

Kay, A. (2012). Operational amplifier noise: techniques and tips for analyzing and reducing noise. Elsevier.

Kelley, C.D., Krolick, A., Brunner, L., Burklund, A., Kahn, D., Ball, W.P. and WeberShirk, M., 2014. An affordable open-source turbidimeter. Sensors, 14(4), pp.71427155 .

Kinar, N. J., and Brinkmann, M., 2021. Development of a sensor and measurement platform for water quality observations: design, sensor integration, 3D printing, and open- 
source hardware. PREPRINT (Version 1) available at Research Square [https://doi.org/10.21203/rs.3.rs$449278 / \mathrm{v} 1]$

Kineke, G.C. and Sternberg, R.W., 1989. The effect of particle settling velocity on computed suspended sediment concentration profiles. Marine Geology, 90(3), pp.159-174.

Kitchener, B.G., Dixon, S.D., Howarth, K.O., Parsons, A.J., Wainwright, J., Bateman, M.D., Cooper, J.R., Hargrave, G.K., Long, E.J. and Hewett, C.J., 2019. A low-cost bench-top research device for turbidity measurement by radially distributed illumination intensity sensing at multiple wavelengths. HardwareX, 5, p.e00052.

Koydemir, H.C., Rajpal, S., Gumustekin, E., Karinca, D., Liang, K., Göröcs, Z., Tseng, D. and Ozcan, A., 2019. Smartphone-based turbidity reader. Scientific reports, 9(1), pp.1-11.

Lyman, T.P., Elsmore, K., Gaylord, B., Byrnes, J.E. and Miller, L.P., 2020. Open Wave Height Logger: An open source pressure sensor data logger for wave measurement. Limnology and Oceanography: Methods, 18(7), pp.335-345.

Nowacki, D.J., Ogston, A.S., Nittrouer, C.A., Fricke, A.T., Asp, N E., and Souza Filho, P.W.M., 2019. Seasonal, tidal, and geomorphic controls on sediment export to Amazon River tidal floodplains. Earth Surface Processes and Landforms, 44(9), 18461859.

O'Dea, A., Brodie, K. L., and Hartzell, P., 2019. Continuous coastal monitoring with an automated terrestrial lidar scanner. Journal of Marine Science and Engineering, 7(2), 37. https://doi.org/10.3390/jmse7020037

Ogston, A.S., Cacchione, D.A., Sternberg, R.W. and Kineke, G.C., 2000. Observations of storm and river flood-driven sediment transport on the northern California continental shelf. Continental Shelf Research, 20(16), pp.2141-2162.

Osborne, P. D., Vincent, C. E. (1996). Vertical and horizontal structure is suspended sand concentrations and wave-induced fluxes over bedforms. Marine geology, 131(34), 195-208.

Ouillon, S., Douillet, P. and Andréfouët, S., 2004. Coupling satellite data with in situ measurements and numerical modeling to study fine suspended-sediment transport: a study for the lagoon of New Caledonia. Coral Reefs, 23(1), pp.109-122. 
Pearce, J.M., 2012. Building research equipment with free, open-source hardware. Science, 337(6100), pp.1303-1304.

Puleo, J. A., Johnson, R. V., Butt, T., Kooney, T. N., Holland, K. T. (2006). The effect of air bubbles on optical backscatter sensors. Marine Geology, 230(1-2), 87-97.

Rasmussen, P.P., Gray, J.R., Glysson, G.D. and Ziegler, A.C., 2009. Guidelines and procedures for computing time-series suspended-sediment concentrations and loads from in-stream turbidity-sensor and streamflow data. US geological survey techniques and methods, book, 3, p.52.

Reeves, I. R. B., Goldstein, E. B., Anarde, K, Moore, L. J., (2021), Remote bed-level change and overwash observation with low-cost ultrasonic distance sensors, Shore Beach. 89(2), 23-30. http://doi.org/10.34237/1008923

Reine, K., Clarke, D., Dickerson, C. and Pickard, S., 2007, May. Assessment of potential impacts of bucket dredging plumes on walleye spawning habitat in Maumee Bay, Ohio. In Proceedings of the 18th World Dredging Congress (WODCON XVIII) (pp. 619-636).

Ridd, P.V., Day, G., Thomas, S., Harradence, J., Fox, D., Bunt, J., Renagi, O. and Jago, C., 2001. Measurement of sediment deposition rates using an optical backscatter sensor. Estuarine, Coastal and Shelf Science, 52(2), pp.155-163.

Ridd, P., Larcombe, P. (1994). Biofouling control for optical backscatter suspended sediment sensors. Marine Geology, 116(3-4), 255-258.

Schoellhamer, D.H. and Wright, S.A., 2003. Continuous measurement of suspended-sediment discharge in rivers by use of optical backscatterance sensors. IAHS Publication, pp.2836 .

Sleath, J. F. A. (1982). The suspension of sand by waves. Journal of Hydraulic Research, $20(5), 439-452$.

Sternberg, R.W., Shi, N.C., Downing, J.P., 1989. Continuous measurements of suspended sediment. In: Seymour, R.J. (Ed.), Nearshore Sediment Transport. Plenum Press, New York, p. 418. 
Storlazzi, C.D., Norris, B.K. and Rosenberger, K.J., 2015. The influence of grain size, grain color, and suspended-sediment concentration on light attenuation: Why finegrained terrestrial sediment is bad for coral reef ecosystems. Coral Reefs, 34(3), pp.967975

Stubblefield, A.P., Reuter, J.E., Dahlgren, R.A. and Goldman, C.R., 2007. Use of turbidometry to characterize suspended sediment and phosphorus fluxes in the Lake Tahoe basin, California, USA. Hydrological Processes: An International Journal, 21(3), pp.281-291.

Talke, S.A. and Stacey, M.T., 2008. Suspended sediment fluxes at an intertidal flat: the shifting influence of wave, wind, tidal, and freshwater forcing. Continental Shelf Research, 28(6), pp.710-725.

Temple, N.A., Webb, B.M., Sparks, E.L. and Linhoss, A.C., 2020. Low-Cost Pressure Gauges for Measuring Water Waves. Journal of Coastal Research, 36(3), pp.661-667.

Thomas, S., Ridd, P.V. and Renagi, O., 2003. Laboratory investigation on the effect of particle size, water flow and bottom surface roughness upon the response of an upwardpointing optical backscatter sensor to sediment accumulation. Continental Shelf Research, 23(16), pp.1545-1557.

Tinoco, R. O., and Coco, G., (2018). Turbulence as the main driver of resuspension in oscillatory flow through vegetation. Journal of Geophysical Research: Earth Surface 123(5), 891-904.

Valenzuela, C., Sosa, C., del Refugio Castañeda, M., Palomeque, J. and Amaro, I.A., 2018. Turbidity Measurement System for Aquaculture Effluents Using an Open-Source Software and Hardware. Nature Environment and Pollution Technology, 17(3), pp.957961.

Vincent, C. E., Hanes, D. M. (2002). The accumulation and decay of near-bed suspended sand concentration due to waves and wave groups. Continental shelf research, 22(14), 1987-2000.

Wang, P. and Beck, T.M., 2017. Determining dredge-induced turbidity and sediment plume settling within an intracoastal waterway system. Journal of Coastal Research, 33(2), pp.243-253. 
Whyte, D.C. and Kirchner, J.W., 2000. Assessing water quality impacts and cleanup effectiveness in streams dominated by episodic mercury discharges. Science of the Total Environment, 260(1-3), pp.1-9.

Wickert, A. D., Sandell, C. T., Schulz, B., Ng, G. H. C. (2019). Open-source Arduinocompatible data loggers designed for field research. Hydrology and Earth System Sciences, 23(4), 2065-2076.

Wiranto, G., Hermida, I.D.P. and Fatah, A., 2016, August. Design and realisation of a turbidimeter using TSL250 photodetector and Arduino microcontroller. In 2016 IEEE International Conference on Semiconductor Electronics (ICSE) (pp. 324-327). IEEE.

Zhu, Y., Cao, P., Liu, S., Zheng, Y. and Huang, C., 2020. Development of a New Method for Turbidity Measurement Using Two NIR Digital Cameras. ACS omega, 5(10), pp.54215428. 


\section{Appendix A: Material list}

Table 2 provides the list of components and associated costs for a single sensor. The actual sensor cost also includes capital investment in supplies like a soldering iron, air compressor, pressure pot, silicone mats, heat gun, and multimeter for circuit construction, epoxy pours, and circuit testing. A few hours of technician time are needed to construct each sensor and housing. The epoxy setup requires about 30 minutes (plus time to cure overnight). A batch of seven endcaps can be produced on a 3D printer in approximately 6 hours using $50 \%$ fill and 76 grams of material. One board can be soldered in 20-30 minutes. The remaining housing construction requires 5-10 minutes per unit. Housing endcaps are allowed to cure overnight after being glued. Some additional time should be budgeted for instrument calibration and programming prior to deployment. 
Table 2: Schedule of materials and costs for one sensor. Note that costs reflect materials purchased in bulk quantities, e.g., packs of 5 or more for breakout boards, and packs of 100 for resistors, diodes, $\mathrm{PC}$ boards, etc.

\begin{tabular}{|c|c|c|c|c|}
\hline Item & Qty & Example product & $\begin{array}{l}\text { Unit } \\
\text { Cost }^{*}\end{array}$ & $\begin{array}{l}\text { Total } \\
\text { Cost } \\
\end{array}$ \\
\hline Microcontroller & 1 & Arduino Nano & $\$ 4.50$ & $\$ 4.50$ \\
\hline ADC module & 1 & $\begin{array}{l}\text { HiLetgo ADS1115 } 16 \text { Bit 16 Byte } 4 \text { Channel } \\
\text { I2C ПC }\end{array}$ & $\$ 4.00$ & $\$ 4.00$ \\
\hline Clock module & 1 & Adafruit DS3231 Precision RTC Breakout & $\$ 2.20$ & $\$ 2.20$ \\
\hline SD card module & 1 & $\begin{array}{l}\text { Micro SD TF card reader module with SPI } \\
\text { interface and chip level conversion }\end{array}$ & $\$ 1.90$ & $\$ 1.90$ \\
\hline MicroSD card & 1 & SanDisk 32 GB & $\$ 7.00$ & $\$ 7.00$ \\
\hline Battery clip & 1 & $\begin{array}{l}2 \text { AA battery polypropylene plastic with } \\
\text { spring contacts }\end{array}$ & $\$ 1.50$ & $\$ 1.50$ \\
\hline Battery & 1 & Lithium 3.6V high-capacity & $\$ 7.00$ & $\$ 7.00$ \\
\hline IR emitter diode & 1 & $\begin{array}{l}\text { VSMF4720-GS08 from DigiKey ( } 870 \mathrm{~nm} \text {, } \\
1.45 \mathrm{~V}, 100 \mathrm{~mA}, 120 \mathrm{deg} \text {; surface mount) }\end{array}$ & $\$ 0.82$ & $\$ 0.82$ \\
\hline IR receiver diode & 1 & $\begin{array}{l}\text { SFH } 235 \text { FA from DigiKey (900nm radial } \\
\text { sensor photodiode, } 20 \mathrm{~ns}, 130 \mathrm{deg})\end{array}$ & $\$ 1.34$ & $\$ 1.34$ \\
\hline Op amp & 1 & MCP6244-E/P from DigiKey & $\$ 0.63$ & $\$ 0.63$ \\
\hline Mosfet switch & 1 & $\begin{array}{l}\text { SI2329DS-T1-GE3 from DigiKey (8V, 6A; } \\
\text { surface mount) }\end{array}$ & $\$ 0.62$ & $\$ 0.62$ \\
\hline $0.1 \mathrm{uF}$ ceramic capacitor & 1 & E-Projects (50V) & $\$ 0.24$ & $\$ 0.24$ \\
\hline $22 \mathrm{pF}$ ceramic capacitor & 1 & E-Projects $(50 \mathrm{~V})$ & $\$ 0.24$ & $\$ 0.24$ \\
\hline 2n3904 npn transistor & 2 & Generic (40V 200mA 300MHz 625mW) & $\$ 0.05$ & $\$ 0.10$ \\
\hline Protoboard & 1 & & $\$ 0.20$ & $\$ 0.20$ \\
\hline Custom-printed PC board & 1 & & $\$ 1.05$ & $\$ 1.05$ \\
\hline Electrical wire & 1 & & $\$ 0.50$ & $\$ 0.50$ \\
\hline Solder & 1 & & $\$ 0.20$ & $\$ 0.20$ \\
\hline Hot glue & 1 & & $\$ 0.20$ & $\$ 0.20$ \\
\hline Resistors & & & & \\
\hline $82 \mathrm{ohm}(1 / 2$ watt $)$ & 1 & Generic & $\$ 0.05$ & $\$ 0.05$ \\
\hline $100 \mathrm{ohm}$ (1/4 watt) & 2 & Generic & $\$ 0.05$ & $\$ 0.10$ \\
\hline 220 ohm (1/4 watt) & 1 & Generic & $\$ 0.05$ & $\$ 0.05$ \\
\hline 10k ohm (1/4 watt) & 2 & Generic & $\$ 0.05$ & $\$ 0.10$ \\
\hline $100 \mathrm{k} \mathrm{ohm} \mathrm{(1/4} \mathrm{watt)}$ & 4 & Generic & $\$ 0.05$ & $\$ 0.20$ \\
\hline $220 \mathrm{k} \mathrm{ohm} \mathrm{(1/4} \mathrm{watt)}$ & 4 & Generic & $\$ 0.05$ & $\$ 0.20$ \\
\hline 330k ohm (1/4 watt) & 1 & Generic & $\$ 0.05$ & $\$ 0.05$ \\
\hline $470 \mathrm{k} \mathrm{ohm} \mathrm{(1/4} \mathrm{watt)}$ & 1 & Generic & $\$ 0.05$ & $\$ 0.05$ \\
\hline $1 \mathrm{M} \mathrm{ohm} \mathrm{(1/4} \mathrm{watt)}$ & 1 & Generic & $\$ 0.05$ & $\$ 0.05$ \\
\hline $11 / 2$ " PVC pipe & 1 & Schedule $40,8-1 / 2$ " length & $\$ 1.30$ & $\$ 1.30$ \\
\hline 3D printed end cap & 1 & Custom & $\$ 2.00$ & $\$ 2.00$ \\
\hline Compression plug & 1 & $\begin{array}{l}\text { Wing nut expansion plug for } 1-1 / 2 \text { " pipe, } 17 \\
\text { PSI maximum, yellow/black (McMaster Carr) }\end{array}$ & $\$ 6.10$ & $\$ 6.10$ \\
\hline Epoxy & 1 & $\begin{array}{l}\text { Vivid Scientific hard optically clear water- } \\
\text { based epoxy }\end{array}$ & $\$ 0.80$ & $\$ 0.80$ \\
\hline & & \multicolumn{2}{|c|}{ Total materials cost per sensor } & $\$ 45.29$ \\
\hline
\end{tabular}

